Original Research Paper

\title{
Enhancement of Immunological Responses by Dietary Arthrospira platensis and Possibility of Field Applications as Alternative to Antibiotics in Broiler Chicken
}

\author{
${ }^{1}$ Shinsuke Katayama, ${ }^{2}$ Yumi Kayahara and ${ }^{2}$ Tomoko Watanabe \\ ${ }^{1}$ Kagawa Prefectural Eastern Regional Livestock Hygiene Service Center, Kagawa, Japan \\ ${ }^{2}$ Kagawa Prefectural Livestock Experiment Station, Japan
}

\author{
Article history \\ Received: $27-05-2015$ \\ Revised: 25-07-2015 \\ Accepted: 29-02-2016 \\ Corresponding Author: \\ Shinsuke Katayama \\ Kagawa Prefectural Eastern \\ Regional Livestock Hygiene \\ Service Center, Kagawa, Japan \\ E-mail: ca0165@pref.kagawa.lg.jp
}

\begin{abstract}
Arthrospira platensis is one of the candidates expected to replace antibiotics by its immunostimulatory effects in broiler industry, but the evaluation aimed at field applications is not enough. Here, we measured general immunological indicators such as specific antibody responses against sheep red blood cell and Brucella abortus, serum immunoglobulin concentrations and monocyte phagocytic capacity of broiler chickens, which assigned to four dietary treatment groups: $A$. platensis at $0,0.01,0.1$ and $1 \%$ was added to their normal feed. Then, the 0.01 to $1 \%$ groups were compared to the $0 \%$ group. In specific antibody responses, the $0.1 \%$ group maintained a higher antibody titer against sheep red blood cells, while the $0.01 \%$ group did against Brucella abortus after the secondary response. Regarding serum immunoglobulin concentrations, IgG levels of the 0.1 and $1 \%$ groups were significantly higher, while IgA levels showed no significant differences. In the phagocytosis assay, each supplemented group showed an increase of the phagocytic capacity of blood monocytes. In several tests, the $1 \%$ group presented heteroscedasticity, i.e., some individuals showed high responses, while others presented poor responses. These observations indicate that dietary $A$. platensis enhances not systemic but some particular immune responses in broiler chickens and a high level of supplementation may inhibit this effect. Therefore, a dietary supplementation of $0.1 \%$ of $A$. platensis with some immunomodulatory substances that enhance mucosal immunity is suitable for upregulating the systemic immune response in broiler chickens.
\end{abstract}

Keywords: Arthrospira, Broiler Chicken, Immune Response, Spirulina

\section{Introduction}

Antimicrobial agents have been used extensively in the broiler chicken industry for a long time and contributed in reducing mortality caused by infectious diseases, thereby improving productivity. However, in recent years, the health authorities of various countries have advocated reductions in the amount of antibiotics used to prevent the increase in microbial resistance (Dibner and Richards, 2005). In Japan, according to the Japanese Veterinary Antimicrobial Resistance Monitoring System, drug-resistant strains have been constantly isolated from healthy broiler chickens (Asai et al., 2006; Harada and Asai, 2010) and the Ministry of Agriculture, Forestry and Fisheries noticed that antimicrobial therapy against poultry-derived bacterial infections in humans is difficult due to their drug resistance. Especially, the high usage of new quinolones increases the risk of inducing resistant Campylobacter spp. Consequently, the broiler chicken industry has been actively looking for alternatives to antibiotics.

Arthrospira platensis (A. platensis), also known as spirulina (blue-green alga), is one of the candidates 
expected to replace antibiotics. This alga has been used as food through the ages (Ciferri, 1983) and has recently been applied as an animal feed supplement with increased interest due to its biological effects (Belay et al., 1996; de Morais et al., 2014). In broiler chickens, $A$. platensis was reported to upregulate some immune responses such as phagocytic capacity and nitrite production of abdominal exudate macrophages and antibody production against sheep Red Blood Cells (sRBC) (Qureshi et al., 1996; Al-Batshan et al., 2001). However, the results were not enough in order to disseminate this alga as an alternative to antibiotics. One problem was that the recommended A. platensis concentrations $(0.5-1.0 \%)$ were too costly to be used commercially. In Japan, the production cost per one broiler chicken would be increased by approximately 70 cents in the case of $1.0 \%$ concentration at the time of writing. Another was that the results had not evaluated an enhancement of systemic immune responses because only one local macrophages had been used and only one specific antibody had been measured in these reports. There is necessary to evaluate more systemic immunological indicators such as serum immunoglobulin (Ig) levels and the phagocytic activity of the monocytes i.e., the macrophage precursor cells in broiler chicken.

In this study, we evaluate the possibility of field applications of dietary A. platensis as an alternative to antibiotics by reference to antibody responses of two specific antigens sRBC and Brucella abortus (BA), serum IgG and IgA levels and phagocytic capacity of peripheral monocytes.

\section{Materials and Methods}

\section{Experimental Chickens}

A total of 400 commercial male Ross broiler chickens were randomly assigned to four dietary treatment groups at one day of age (average initial bodyweight was $41.2 \mathrm{~g}$ ). The animals in each group were fed a mash basal diet mixed with $0,0.01,0.1$ and $1 \%$ of $A$. platensis (DIC LIFETEC Co., Ltd. Tokyo, Japan), respectively. The basal diet consisted mainly of corn and soybean and adapted to the official standard of the Feed Safety Law of Japan (Table 1). The nutrition information of current $A$. platensis is presented in Table 2. Each nutrient component of this alga was approximately similar to the general one, according to the USDA National Nutrient Database for Standard Reference. The use of antibiotics was reduced as much as possible, i.e., the basal diet did not include any antibiotics and all chickens were administered a combination of sulfamonomethoxine and ormetoprim only at 21 to 23 days of age as prophylactics against coccidiosis. Feed and water were provided ad libitum and chickens were fed these diets throughout the study period. All animals were vaccinated against fowlpox, Marek's disease, Newcastle disease, avian infectious bronchitis and infectious bursal disease. All experiments were approved by the Ethical Review Board of Kagawa Prefectural Livestock Experiment Station and conformed to the provisions of the Declaration of Helsinki.

\section{Humoral Immunity}

sRBC and killed BA were used as test antigens to quantitate specific antibody responses. Ten chickens from each treatment group were immunized intravenously via a wing vein with $0.1 \mathrm{~mL}$ of $5 \% \mathrm{sRBC}$ and $1 \%$ BA suspension prepared in $0.9 \%$ sterile saline at 3 and 4 weeks of age. Blood samples were collected weekly from 4 to 7 weeks of age. Antibody levels were quantitated using an agglutination test. The maximal serum dilution rate that agglutinates half of $1 \%$ antigen solution was defined as the antibody titer.

\section{Immunoglobulin Quantumy}

Serum $\operatorname{IgA}$ and $\operatorname{IgG}$ were measured to calculate the systemic antibody producibility. Blood sera were collected from ten birds, different from the sRBC and BA immunized animals, at 5 and 7 weeks of age and each immunoglobulin was measured by using a Chicken IgA and IgG ELISA Kit (BETHYL Laboratories, Inc. Montgomery, Texas, US.).

Table 1. The nutrient information of basal diet

\begin{tabular}{lll}
\hline & 1 to 21 days of age & 22 to 49 days of age \\
\hline Crude protein (\%) & 23.26 & 19.98 \\
Crude fat $(\%) *$ & 4.0 & 4.0 \\
Crude fiber (\%)* & 5.0 & 5.0 \\
Crude ash (\%) & 5.54 & 5.26 \\
$\mathrm{Ca}(\%) *$ & 0.80 & 0.80 \\
$\mathrm{P}(\%) *$ & 0.50 & 0.45 \\
Metabolizable energy $(\mathrm{kcal} / \mathrm{kg}) *$ & 3,100 & 3,250 \\
\hline
\end{tabular}

* The numbers are estimated values calculated from raw materials. Metabolizable Energy (ME) were calculated from sum of the products of the mixing ratio and each ME, which was defined by Feed Safety Law of Japan 
Table 2. The nutrient information of $A$. platensis

\begin{tabular}{|c|c|c|}
\hline & Unit & Value per $100 \mathrm{~g}$ \\
\hline \multicolumn{3}{|l|}{ Proximates } \\
\hline Water & g & 4.6 \\
\hline Protein & $\mathrm{g}$ & 70.0 \\
\hline Total lipid & $\mathrm{g}$ & 8.2 \\
\hline Carbohydrate & $\mathrm{g}$ & 3.9 \\
\hline Fiber & g & 7.7 \\
\hline \multicolumn{3}{|l|}{ Minerals } \\
\hline Sodium & $\mathrm{mg}$ & 300 \\
\hline Phosphorus & $\mathrm{mg}$ & 906 \\
\hline Iron & $\mathrm{mg}$ & 48.2 \\
\hline Calcium & $\mathrm{mg}$ & 66.3 \\
\hline Potassium & $\mathrm{mg}$ & 1.72 \\
\hline Magnesium & $\mathrm{mg}$ & 250 \\
\hline Copper & $\mathrm{mg}$ & 0.21 \\
\hline Zinc & $\mathrm{mg}$ & 1.08 \\
\hline Manganese & $\mathrm{mg}$ & 3.30 \\
\hline \multicolumn{3}{|l|}{ Vitamins } \\
\hline beta-carotene & $\mu \mathrm{g}$ & 240,000 \\
\hline Thiamin & $\mathrm{mg}$ & 4.80 \\
\hline Riboflavin & $\mathrm{mg}$ & 4.14 \\
\hline VB6 & $\mathrm{mg}$ & 1.18 \\
\hline VB12 & $\mathrm{mg}$ & 0.27 \\
\hline alpha-tocopherol & $\mathrm{mg}$ & 9.3 \\
\hline \multicolumn{3}{|l|}{ Other } \\
\hline Linoleic acid & g & 1.38 \\
\hline gamma-linolenic acid & $\mathrm{g}$ & 1.28 \\
\hline C-phycocyanin & $\mathrm{mg}$ & 7,510 \\
\hline
\end{tabular}

\section{Cell-Mediated Immunity}

Monocyte phagocytic capacity was examined as cellmediated immunity. Blood samples were collected from ten chickens from each treatment group, different from the sRBC and BA immunized animals, at 7 weeks of age. Mononuclear blood cells were collected from each whole blood sample using Ficoll-Hypaque solution (Sumitomo Dainippon Pharma Co., Ltd. Osaka, Japan.) and incubated in chamber slides overnight $\left(37^{\circ} \mathrm{C}, 5 \%\right.$ $\mathrm{CO}_{2}$ ). Adherent cells were then incubated with $1.1 \mu \mathrm{m}$ latex beads for one hour $\left(37^{\circ} \mathrm{C}, 5 \% \mathrm{CO}_{2}\right)$ and monocytes that phagocytized more than three latex beads were counted as phagocytic monocytes.

\section{Statistical Analysis}

$F$-test was used to confirm the homoscedasticity between the 0.01 to $1 \%$ groups and the $0 \%$ group. The 0.01 to $1 \%$ groups were then compared with the $0 \%$ group using the Student's $t$-test or Welch's $t$-test. Each $P$ value was corrected by using the Bonferroni correction test. $P$ values less than 0.05 were considered statistically significant.

\section{Results}

\section{Anti-sRBC and Anti-BA Antibody Responses}

The results are presented in Table 3 (anti-sRBC) and Table 4 (anti-BA). All birds responded against each antigen and thrived without visible disorders. No significant difference was observed during the primary (at 4 weeks of age) and secondary (at 5 weeks of age) antibody responses. The $0.1 \%$ group showed a significantly higher titer than the $0 \%$ group at 6 weeks of age in the sRBC test, while the $0.01 \%$ group did in the BA test. These groups maintained higher titers at 7 weeks of age, but there was no significant difference. The titers of the $1 \%$ group were highly variable compared to those of the $0 \%$ group at 5 weeks of age (against-sRBC) and 6 weeks of age (against-BA).

\section{Quantities of $\operatorname{Ig} A$ and $\operatorname{Ig} G$}

The serum $\operatorname{IgA}$ and $\operatorname{IgG}$ data are presented in Fig. 1. The average IgA levels were not significantly different among the groups. The average IgG level of the $0.1 \%$ group was significantly higher at 5 and 7 weeks of age. On the other hand, the average $\operatorname{IgG}$ level of the $1 \%$ group was significantly higher at 5 weeks of age, but not significantly different at 7 weeks of age. In addition, IgG concentration of the $1 \%$ group showed heteroscedasticity at 5 weeks of age.

\section{Phagocytic Monocyte Rates}

The individual percentage of phagocytic monocytes dots is presented in Fig. 2. The average percentage of phagocytic monocytes was significantly higher in each supplementation group and the averages increased in 
proportion to the concentration of A. platensis in the diet. Although the $1 \%$ group did not show

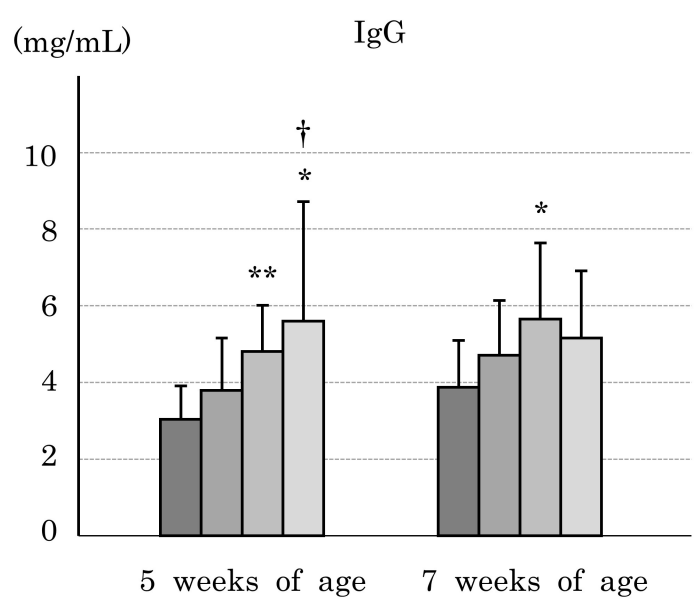

heteroscedasticity, two individuals in this group showed poor phagocytic capacity.

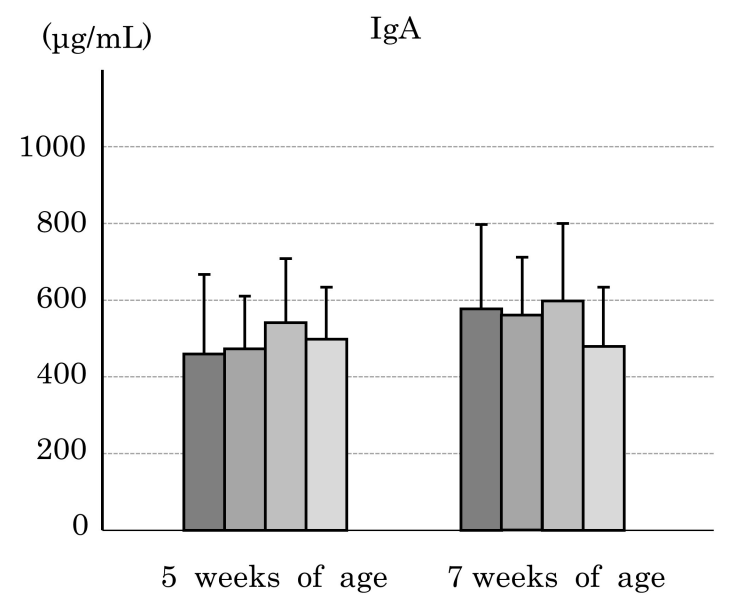

$\square 0 \% \quad \square \quad 0.01 \% \quad \square \quad 0.1 \% \quad \square \quad 1 \%$

Fig. 1. Serum immunoglobulin concentration of each dietary group (Mean $\pm \mathrm{SD}$ ). ${ }^{*} \mathrm{p}<0.05,{ }^{*} \mathrm{p}<0.01$ : Significant differences compared with $0 \%$ group. $\uparrow$ : Unequal variance from $0 \%$ group

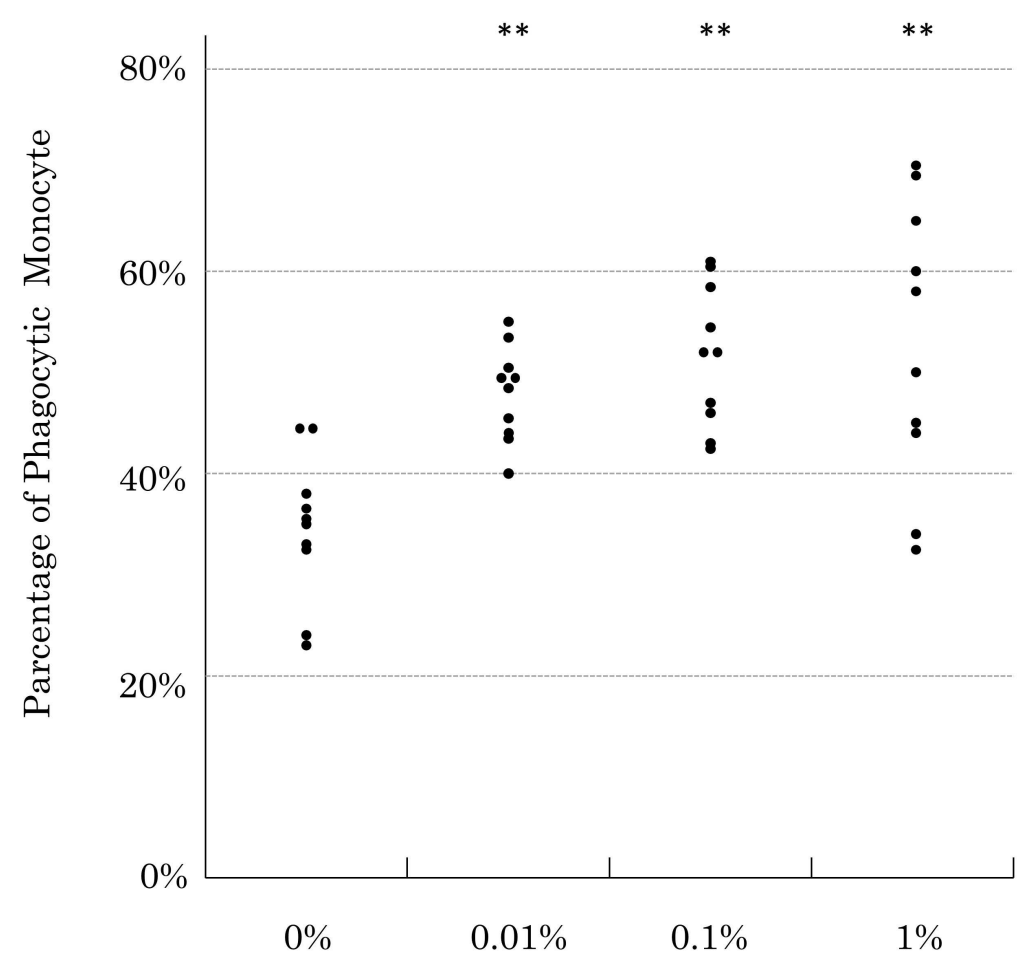

\section{A. platensis}

Fig. 2. Percentage of phagocytic macrophage in individual chicken. ${ }^{* *} \mathrm{p}<0.01$ : The average of percentage was significantly different compared with $0 \%$ group 
Table 3. Anti-sRBC ${ }^{\text {a }}$ antibody response ${ }^{\mathrm{b}}$

\begin{tabular}{|c|c|c|c|c|}
\hline \multirow[b]{2}{*}{ A. platensis } & \multicolumn{4}{|l|}{ Age (weeks) } \\
\hline & $4 \mathrm{w}\left(1^{\text {st }}\right.$ response $)$ & $5 \mathrm{w}\left(2^{\text {nd }}\right.$ response $)$ & $6 w$ & $7 \mathrm{w}$ \\
\hline $0 \%$ & $3.1 \pm 1.4$ & $5.8 \pm 0.6$ & $3.4 \pm 0.5$ & $3.1 \pm 0.9$ \\
\hline $0.01 \%$ & $3.3 \pm 1.3$ & $6.1 \pm 0.9$ & $3.7 \pm 0.8$ & $3.4 \pm 1.0$ \\
\hline $0.1 \%$ & $3.5 \pm 1.4$ & $6.2 \pm 1.0$ & $4.2 \pm 0.6^{* *}$ & $3.9 \pm 1.1$ \\
\hline $1 \%$ & $3.8 \pm 1.0$ & $5.5 \pm 1.7 \dagger$ & $3.5 \pm 0.7$ & $3.8 \pm 0.9$ \\
\hline
\end{tabular}

a: Sheep Red Blood Cell; $b$ : Data is the mean \pm SD of Log2 anti-sRBC titers; **: Significant difference compared with $0 \%$ group $(p<0.01) ; \dagger$ : Unequal variance from $0 \%$ group.

Table 4. Anti-BA ${ }^{\mathrm{a}}$ antibody response ${ }^{\mathrm{b}}$

\begin{tabular}{|c|c|c|c|c|}
\hline \multirow[b]{2}{*}{ A. platensis } & \multicolumn{4}{|l|}{ Age (weeks) } \\
\hline & $4 \mathrm{w}\left(1^{\text {st }}\right.$ response $)$ & $5 \mathrm{w}\left(2^{\text {nd }}\right.$ response $)$ & $6 w$ & $7 \mathrm{w}$ \\
\hline $0 \%$ & $4.4 \pm 1.6$ & $5.0 \pm 1.2$ & $3.2 \pm 0.6$ & $3.0 \pm 0.9$ \\
\hline $0.01 \%$ & $3.8 \pm 1.1$ & $5.6 \pm 0.8$ & $4.1 \pm 1.0^{*}$ & $3.9 \pm 1.0$ \\
\hline $0.1 \%$ & $4.1 \pm 1.2$ & $5.2 \pm 0.9$ & $3.8 \pm 0.8$ & $3.1 \pm 0.9$ \\
\hline $1 \%$ & $4.9 \pm 1.2$ & $5.5 \pm 1.4$ & $3.9 \pm 1.7 \dagger$ & $3.7 \pm 1.3$ \\
\hline
\end{tabular}

a: Brucella abortus; $b$ : Data is the mean \pm SD of Log2 anti-BA titers; *: Significant difference compared with $0 \%$ group (p<0.05); $\uparrow$ : unequal variance from $0 \%$ group.

\section{Discussion}

In this study, we described the enhancement of immune responses by dietary $A$. platensis using various assays at lower doses compared to previous studies. In the specific antibody responses, we immunized chickens against both sRBC and BA. It is generally accepted that sRBC is a T-cell-dependent antigen and BA is a T-cellindependent (B-cell-dependent) antigen (Gilmour et al., 1970; Toivanen et al., 1972; Hirota et al., 1980; Karaca et al., 1999). The difference between each antibody response suggests that the suitable dosage of $A$. platensis to stimulate each immunocompetent cell is different. In the serum immunoglobulin quanta, IgG level was clearly increased by $A$. platensis supplementation except in the $1 \%$ group at 7 weeks of age. In the $1 \%$ group at 7 weeks of age, the immunostimulatory effect of $A$. platensis seemed to be countered partially by overdose toxicity of itself, along with the increase of the total intake of experimental food. On the other hand, IgA level did not increase by $A$. platensis supplementation. It is well known that IgG production is stimulated by interleukin-4 or interferon gamma, while IgA production is stimulated by interleukin-5 in humans and mice (Janeway et al., 2001; Male et al., 2006). Although our knowledge of the mechanism of immunoglobulin production and interaction of cytokines such as interleukin and interferon in fowls is insufficient, this difference in immunoglobulin production indicates that dietary $A$. platensis affects a particular cytokine production that increases IgG producibility. However, additional investigations of immunological indicators in mucosal membrane are necessary to confirm that dietary $A$. platensis does not influence IgA production because IgA-producing cells are mainly localized in the mucosa where they produce IgA (Lebacq-Verheyden et al., 1974). The monocyte phagocytic activity increased significantly by low A. platensis dosage compared to previous study. It is likely that the macrophage phagocytic capacity is stimulated similarly by low $A$. platensis dosage regardless of the distribution region. Altogether, these results suggest that an immunomodulatory compound of $A$. platensis may not affect systemic immunoreactivity, but particular immunocompetent cells or immune cytokine production such as interferon gamma, which was reported to stimulate macrophage activity and specific antibody production (Weining et al., 1996; Lowenthal et al., 1998; He et al., 2011).

Another interesting finding was the heteroscedasticity observed in the $1 \%$ A. platensis supplemented group. In this group, some individuals showed higher responses, while others presented poor or no responses when compared with the $0 \%$ group. This result suggests that a highly concentrated supplementation of $A$. platensis may negate the beneficial effect of this alga. Although the cause of this adverse effect remains unclear, this phenomenon is undesirable because an individual, who presents a weak immune response, may amplify various infectious agents in its broiler chicken group. Therefore, we recommend a supplementation with up to $0.1 \%$ of $A$. platensis. Further studies regarding immunosuppressive mechanisms such as regulatory T-cell activity (Shanmugsundaram and Selvaraj, 2001) or overdose toxicity by dietary $A$. platensis are necessary in order to supplement $A$. platensis without this adverse effects. 


\section{Conclusion}

A. platensis presents some immunomodulatory effects that enhance macrophage activity and IgG productivity, but not IgA. Therefore, another additive that modulates the mucosal immune system is necessary. For example, several bacteria have been commercially used as probiotics that modulate gut immunity in the chicken industry (Haghighi et al., 2006; Fajardo et al., 2012; Qiu et al., 2012). Currently, 0.1\% A. platensis supplementation with complementary substances that modulate the mucosal immunity is recommended to enhance the systemic immune response in broiler chickens. This concentration will be accepted from the poultry farmers in terms of cost. Further investigations, designed to induce experimental infections, are necessary to determine whether this alga can be used as a replacement of antimicrobial agents for the control of infectious diseases.

\section{Acknowledgment}

This work was funded by DIC LIFETEC Co., Ltd who provided A. platensis and its nutrition information.

\section{Author's Contributions}

Shinsuke Katayama: Conducted the animal experiment, summarized the data and wrote the manuscript.

Yumi Kayahara: Contributed to the animal experiment.

Tomoko Watanabe: Contributed to the animal experiment.

\section{Ethics}

This article is original and contains unpublished material. The corresponding author confirms that all of the other authors have read and approved the manuscript and no ethical issues involved.

\section{References}

Al-Batshan, H.A., S.I. Al-Mufarrej, A.A. Al-Homaidan and M.A. Qureshi, 2001. Enhancement of chicken macrophage phagocytic function and nitrite production by dietary Spirulina platensis. Immunopharmacol. Immunotoxicol., 23: 281-289. DOI: $10.1081 /$ IPH-100103866

Asai, T., H. Esaki, A. Kojima, K. Ishihara and Y. Tamura et al., 2006. Antimicrobial resistance in Salmonella isolates from apparently healthy foodproducing animal from 2000 to 2003: The first stage of Japanese Veterinary Antimicrobial Resistance Monitoring (JVARM). J. Vet. Med. Sci., 68: 881-884. DOI: $10.1292 /$ jvms.68.881
Belay, A., T. Kato and Y. Ota, 1996. Spirulina (Arthrospira): Potential application as an animal feed supplement. J. Appl. Phycol., 8: 303-311. DOI: $10.1007 / \mathrm{BF} 02178573$

Ciferri, O., 1983. Spirulina, the edible microorganism. Microbio. Rev., 47: 551-578.

Dibner, J.J. and J.D. Richards, 2005. Antibiotic growth promoters in agriculture: History and mode of action. Poul. Sci., 84: 634-643. DOI: 10.1093/ps/84.4.634

Fajardo, P., L. Pastrana, J. Méndez, I. Rodríquez and C. Fuciños et al., 2012. Effects of feeding of two potentially probiotic preparations from lactic acid bacteria on the performance and faecal microflora of broiler chickens. Scientific World J., 2012: 562635-562643. DOI: 10.1100/2012/562635

Gilmour, D.G., G.A. Theis and G.J. Thorbecke, 1970. Transfer of antibody production with cells from bursa of fabricius. J. Exp. Med., 132: 134-147. DOI: $10.1084 /$ jem.132.1.134

Haghighi, H.R., J. Gong, C.L. Gyles, M.A. Hayes and H. Zhou et al., 2006. Probiotics stimulate production of natural antibodies in chickens. Clin. Vaccine Immunol., 13: 975-98. DOI: 10.1128/CVI.00161-06

Harada, K. and T. Asai, 2010. Role of antimicrobial selective pressure and secondary factors on antimicrobial resistance prevalence in Escherichia coli from food-producing animals in Japan. J. Biomed. Biotechnol., 2012: 180682-180693. DOI: $10.1155 / 2010 / 180682$

He, H., K.J. Genovese and M.H. Kogut, 2011. Modulation of chicken macrophage effector function by $T_{H} 1 / T_{H} 2$ cytokines. Cytokine, 53: 363-369. DOI: 10.1016/j.cyto.2010.12.009

Hirota, Y., T. Suzuki and Y. Bito, 1980. The development of unusual B-cell functions in the testosteronepropionate-treated chicken. Immunology, 39: 29-36. PMID: 6966602

Janeway, C.A. Jr., P. Travers, M. Walport and M.J. Shlomchik, 2001. Immunobiology. 5th Edn., Garland Science, New York.

Karaca, M., E. Johnson and S.J. Lamont, 1999. Genetic line and major histocompatibility complex effects on primary and secondary antibody responses to TDependent and T-Independent antigens. Poult. Sci., 78: 1518-1525. DOI: 10.1093/ps/78.11.1518

Lebacq-Verheyden, A.M., J.P. Vaerman and J.F. Heremans, 1974. Quantification and distribution of chicken immunoglobulins $\operatorname{IgA}, \operatorname{IgM}$ and $\operatorname{IgG}$ in serum and secretions. Immunology, 27: 683-692. PMID: 4215742

Lowenthal, J.W., J.J. York, T.E. O'Neil, R.A. Steven and D.G. Storm et al, 1998. Potential use of cytokine therapy in poultry. Vet. Immunol. Immunopathol., 63: 191-198. DOI: 10.1016/S0165-2427(98)00095-6 
Male, D., J. Brostoff, D. Roth and I. Roitt, 2006. Immunology. 7th Edn., Mosby Elsevier, Missouri.

de Morais, M.G., B.S. Vaz, E.G. de Morais and J.A. Costa, 2014. Biological effects of Spirulina (Arthrospira) biopolymers and biomass in the development of nanostructured scaffolds. BioMed. Res. Int., 2014: 762705-762713. DOI: $10.1155 / 2014 / 762705$

Qiu, R., J. Croom, R.A. Ali, A.L. Ballou, C.D. Smith et al., 2012. Direct fed microbial supplementation repartitions host energy to the immune system. J. Anim. Sci., 90: 2639-2651.

DOI: $10.2527 /$ jas.2011-4611

Qureshi, M.A., J.D. Garlich and M.T. Kidd, 1996. Dietary Spirulina platensis enhances humoral and cell-mediated immune functions in Chickens. Immunopharmacol. Immunotoxicol., 18: 465-476. DOI: $10.3109 / 08923979609052748$
Shanmugsundaram, R. and R.K. Selvaraj, 2011. Regulatory $\mathrm{T}$ cell properties of chicken $\mathrm{CD} 4^{+} \mathrm{CD} 25^{+}$ cells. J. Immunol., 186: 1997-2002.

DOI: $10.4049 /$ jimmunol.1002040

Toivanen, P., A. Toivanen and R.A. Good, 1972. Ontogeny of bursal function in chicken. J. Exp. Med., 136: 816-831. DOI: 10.1084/jem.136.4.816

Weining, K.C., U. Schultz, U. Münster, B. Kaspers and P. Staeheli, 1996. Biological properties of recombinant chicken interferon-gamma. Eur. J. Immunol., 26: 2440-2447.

DOI: $10.1002 /$ ji.1830261026 